\title{
The role of literature in medical education. A commentary on the poem: Roswell, Hanger 84
}

\author{
Robin Downie Glasgow University, Glasgow
}

The use of the arts in health care is increasing in the UK. More specifically, there are three main strands to the movement: the use of the arts as therapy; as an aid to health promotion in communities, and in medical education. I shall deal only with the last, and mainly with the use of literature as a way of developing the ethical sense of students. But, as I shall briefly indicate at the end, literature (and the arts more generally) have a value for medical education and the practice of health care wider than their instrumental use in developing specifically ethical sensitivity. ${ }^{1}$ I have three questions on the narrower instrumental use of literature. Can poems such as that by Dr A A McConnell, ${ }^{2}$ and literature more broadly, be of help in developing ethical sensitivity? If so, is there any room for them in the curriculum? How do they help, and how do they compare with the study of philosophical medical ethics, in the development of a capacity for making the first-order ethical decisions which all doctors and nurses must make?

My answer to the first question is cautious, or even pessimistic. Literature cannot always help, and perhaps poetry least of all the varieties of literature. Partly this may be because large sections of the population, including many doctors and medical students, do not read literature which is at all demanding, and least of all poetry. Partly it is because even those students and doctors who are readers do not make the connection between what they read and their professional practice; they do not view literature as giving rise to transferable skills. But some students do enjoy literature and for them some study of literature may be of help in the development of ethical awareness.

In answer to the second question I can point to the new medical curriculum in the UK. It is possible for medical schools to offer "special study modules", which are blocks of four or five weeks of intensive study of a subject not in the core curriculum. ${ }^{3}$ The General Medical Council in the UK has given encouragement to the idea that some of these should be non-medical, and it is here that medical educators, with the help of their colleagues in the "arts" or "humanities", can offer some literature. It is also the case that some educators at a postgraduate level are considering the study of literature as a relevant subject. Similar possibilities exist in many medical schools, worldwide.

Assuming then that for a minority of students and doctors the study of literature might have a transferable benefit for coping with the ethical problems which arise in their medical practice, and that there is some room for it in medical education, I can move to my third question and ask what that benefit is. What has literature to offer, and how does it compare with "philosophical medical ethics" for the purpose of developing an ethical capacity for dealing with first-order problems?

Let me begin with Dr McConnell's poem. The first thing this poem offers is the encouragement to see human beings in an unusual perspective. Many philosophers are given to congratulating the human race on having a "higher moral status" than the rest of creation. Having plucked this judgment from the air they proceed to draw from it conclusions such as: it is quite all right ethically to cut up any animal, from chimpanzees to pigs, if it will save a human life by providing organs for transplant. The poem encourages us to realise that human beings are "untrainable ... too aggressive, too stupid, too selfish", so that all that can be done is eat them, risking the infecting of the higher species of alien with "Human CJD"! The adoption of a broad perspective of the kind presented in the poem is an important necessary condition for the development of ethical awareness, perhaps especially so in doctors who have a tendency to be narrowly focused. The adjectives "medical" or "health care" or "bio" as qualifiers of the term "ethics" indicate that we are dealing with an approach which is narrow - ethics from the health care point of view. The ethical perspectives offered by literature are much wider, 
and in them doctors, nurses or other human beings, are not always the heroes.

Secondly, this poem and similar literature can offer the specifics of a particular incident. In my experience of teaching medical and nursing ethics over a period of years, students and their elders will listen politely to the outline of ethical theories, but they become interested only when we get on to actual case studies - at which point the ethical theories, or the "four principles", are forgotten. This is no doubt why the case study method is popular in the discussion of first-order medical ethics. But literature also can offer the circumstantial detail of medical cases, but in a wider non-medical perspective. It can be used to supplement rather than supplant these first-order medical cases.

\section{Moral imagination}

Thirdly, literature can offer a stimulus to the moral imagination, ${ }^{4}$ to what we might call "consciousness-raising". There is a marked tendency, picked up by the media, to see medical ethics in terms of what are termed "dilemmas". But not all problems are "dilemmas". We have a problem when we don't know what to do or to think; we have a dilemma when we are already clear that there are two courses which we can take and we cannot decide which is the better. But even if we leave that aside, the ethical failing of many of us, perhaps especially doctors, is not the inability to solve an ethical problem, but the total lack of awareness that there is a problem at all. This is the classic case of moral insensitivity, and it is precisely this which is a common complaint against doctors. No application of principles is at all relevant here, since the fault lies in a failure of imagination or awareness. If this failure can be prevented at all (and I am not optimistic) it is by the stimulation to the imagination which comes from literature. Literature, perhaps especially poetry, can do this in various ways, but the impact of its imagery and language can affect the imagination with a force which the plainer language of philosophy can never use (and should not attempt to).

Defenders of philosophical medical ethics might say here that what philosophy can offer is assistance in the development of analytical skills. ${ }^{5}$ No doubt, but it is a common illusion among philosophers that they have a monopoly of analytical skills. The analysis of a poem is a highly skilled and complex matter, especially since poems are resonant with irony and ambiguity. Indeed, perhaps the diagnosis of a patient's illness and the analysis of an ethical problem have this in common: each is more like the interpretation of a difficult text than like either the scientific analy: of urine or the logical analysis of an argument. ${ }^{6}$ m

What about the justification of a moral decisi in medicine? Literature cannot offer a transferabfe skill here, but neither can philosophical theo $\vec{f}$. Indeed, the truth is that the latter is simply spurioffs in the context of justification, because it is in the wrong logical category to serve as the justification of a first-order moral judgment. Here I differ from Professor Gillon. ${ }^{5}$ For example, "We should stQิ the treatment" might represent a combined technical and moral decision, and "The patient is 70 longer responding to it" might be offered as its juㅎtification. There is no need for a doctor to link the justification to any philosophical theory (although consenting philosophers in private might enjoy dis cussing universalisability or the three sorts of utffPtarianism which might be relevant).

There are various historical reasons why teaching of medical ethics has fallen into the hands of philosophers. Stephen Toulmin has argued that medicine has saved the life of ethics, $\$$ the sense of "moral philosophy". P Perhaps. \&y question here is: what does philosophical medical ethics do to the first-order ethical sensitivity क्Qf doctors and nurses? My answer is that it may kill it! If, for example, students are invited to reag oia case and decide what (a) a deontologist and $\$$ a utilitarian would say, they may feel encouraged go think that philosophical theories are a substiture for the moral sense they bring with them to the experience. Philosophy is certainly one kind क्रि expertise, but it is not a kind which has much bearing on first-order moral decision making.

\section{Lived experience}

The conclusion which I draw from this comparison of philosophy and literature as possible vehicles for teaching first-order medical ethicsois that perhaps neither will make much practical diffference, but at least literature does not attemptgo o substitute abstract principle and foundationalist theory for lived experience. Note that I am not rejecting medical ethics, where that is understod simply as a first-order discussion of the morality $\mathrm{g} f$ various medical practices. Medical ethics just fs $_{\mathrm{s}}$ ordinary morality with a medical content and dọes not need special principles or special theoretißal justification. And of course that kind of first-order discourse is a legitimate subject matter for secondorder philosophical theorising, just as any sort? discourse might be. My point is that second-orबer philosophising is no help in first-order decision making, whereas a study of literature, sometines and for some students, just might be.

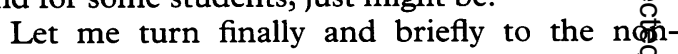
instrumental value of literature and ot 
"humanities" for medical education. In the end (if I may presume to speak for the general public) we want our doctors to be competent and wise. The competence comes from the scientific technicalities of medical training. The wisdom includes ethical sensitivity but is much wider than that, and it mainly comes from being broadly educated. Here, as I hinted at the start, literature and also philosophy may have parts to play. ${ }^{8}$ The humanities are not just instrumental in creating the educated doctor; along with an understanding of the sciences they constitute what it means to be "educated" as distinct from simply "trained".

Robin Downie is Professor of Moral Philosophy in the Department of Philosophy, Glasgow University.

\section{References}

1 Evans M, Greaves D, Pickering N. Medicine, the arts and imagination. Fournal of Medical Ethics 1997;23:254.

2 McConnell AA. Roswell, Hanger 84. Fournal of Medical Ethics 1999;25:528.

3 General Medical Council. Tomorrow's doctors: recommendations on undergraduate medical education. London: General Medical Council, 1993.

4 Scott PA. Imagination in practice. Fournal of Medical Ethics 1997;23:45-50

5 Gillon R. Imagination, literature, medical ethics and medical practice. Fournal of Medical Ethics 1997;23:3-4

6 Hunter KM. Doctors' stories. Princeton: Princeton University Press, 1991.

7 Toulmin S. How medicine saved the life of ethics. In: DeMarco DJ, Fox RM, eds. New directions in ethics. London: Routledge and Kegan Paul, 1986:265-81.

8 Downie RS, Macnaughton J. Should medical students read Plato? The Medical Fournal of Australia 1999;170:125-7.

9 Downie RS, Charlton B. The making of a doctor. Oxford: Oxford University Press, 1992. 